\title{
Using Personality Tests to Identify Potential ICT Entrepreneurs
}

\author{
KA Johnston, B. Andersen, J. Davidge-Pitts and \\ M. Ostensen-Saunders \\ University of Cape Town, Cape Town, South Africa,
}

Kevin.Johnston@uct.ac.za

\begin{abstract}
Literature relating to personality and entrepreneurship has focused primarily on personality characteristics of traditional entrepreneurs. The focus of this study was on personality characteristics and temperaments of potential ICT entrepreneurs.

The main objective of the study was to evaluate the impact of personality characteristics as identifiers of potential ICT entrepreneurship. In order to meet this objective, the personality characteristics of the participants had to be determined. The Keirsey Temperament Sorter was used as a personality indicator, as it is a proven research instrument. Two entrepreneurial tests were used to determine entrepreneurial ability. The temperament of the individuals was ascertained, and compared to their entrepreneurial ability. The population sample used for this study was comprised of third year and honours information systems students from the University of Cape Town, and current ICT entrepreneurs.
\end{abstract}

A positive relationship between the "Martian" temperaments and potential ICT entrepreneurs was found. No significant relationship between specific personality types and potential entrepreneurial ability were evident in the study.

A positive connection was noticed between potential ICT entrepreneurs, and being male. Unfortunately the number of female respondents was insufficient, leading to an inconclusive result.

Key Words: Temperament, personality, entrepreneurial tests, entrepreneurs.

Full version of this paper has been fast-tracked for publication in the Journal of IT Education 